NASA/TM—2014-218121

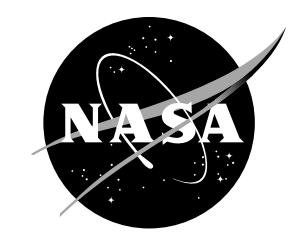

Traveling-Wave Tube Amplifier Second Harmonic as Millimeter-Wave Beacon Source for Atmospheric Propagation Studies

Rainee N. Simons and Edwin G. Wintucky

Glenn Research Center, Cleveland, Ohio 


\section{NASA STI Program . . . in Profile}

Since its founding, NASA has been dedicated to the advancement of aeronautics and space science. The NASA Scientific and Technical Information (STI) program plays a key part in helping NASA maintain this important role.

The NASA STI Program operates under the auspices of the Agency Chief Information Officer. It collects, organizes, provides for archiving, and disseminates NASA's STI. The NASA STI program provides access to the NASA Aeronautics and Space Database and its public interface, the NASA Technical Reports Server, thus providing one of the largest collections of aeronautical and space science STI in the world. Results are published in both non-NASA channels and by NASA in the NASA STI Report Series, which includes the following report types:

- TECHNICAL PUBLICATION. Reports of completed research or a major significant phase of research that present the results of NASA programs and include extensive data or theoretical analysis. Includes compilations of significant scientific and technical data and information deemed to be of continuing reference value. NASA counterpart of peer-reviewed formal professional papers but has less stringent limitations on manuscript length and extent of graphic presentations.

- TECHNICAL MEMORANDUM. Scientific and technical findings that are preliminary or of specialized interest, e.g., quick release reports, working papers, and bibliographies that contain minimal annotation. Does not contain extensive analysis.

- CONTRACTOR REPORT. Scientific and technical findings by NASA-sponsored contractors and grantees.
- CONFERENCE PUBLICATION. Collected papers from scientific and technical conferences, symposia, seminars, or other meetings sponsored or cosponsored by NASA.

- SPECIAL PUBLICATION. Scientific, technical, or historical information from NASA programs, projects, and missions, often concerned with subjects having substantial public interest.

- TECHNICAL TRANSLATION. Englishlanguage translations of foreign scientific and technical material pertinent to NASA's mission.

Specialized services also include creating custom thesauri, building customized databases, organizing and publishing research results.

For more information about the NASA STI program, see the following:

- Access the NASA STI program home page at http://www.sti.nasa.gov

- E-mail your question to help@sti.nasa.gov

- Fax your question to the NASA STI Information Desk at 443-757-5803

- Phone the NASA STI Information Desk at 443-757-5802

- Write to: STI Information Desk NASA Center for AeroSpace Information 7115 Standard Drive Hanover, MD 21076-1320 
NASA/TM-2014-218121

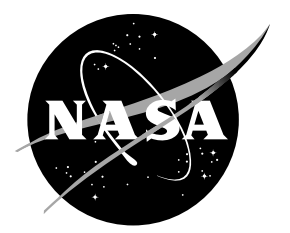

\section{Traveling-Wave Tube Amplifier Second Harmonic as Millimeter-Wave Beacon Source for Atmospheric Propagation Studies}

Rainee N. Simons and Edwin G. Wintucky

Glenn Research Center, Cleveland, Ohio

Prepared for the

International Symposium on Antennas and Propagation and USNC/URSI National Radio Science Meeting sponsored by the Institute of Electrical and Electronics Engineers

Memphis, Tennessee, July 6-12, 2014

National Aeronautics and

Space Administration

Glenn Research Center

Cleveland, Ohio 44135 


\section{Acknowledgments}

The support from the 2012 NASA GRC Center Innovation Fund (CIF) is gratefully acknowledged.

This report contains preliminary findings, subject to revision as analysis proceeds.

Level of Review: This material has been technically reviewed by technical management.

Available from

NASA Center for Aerospace Information 7115 Standard Drive

Hanover, MD 21076-1320
National Technical Information Service 5301 Shawnee Road Alexandria, VA 22312

Available electronically at http://www.sti.nasa.gov 


\title{
Traveling-Wave Tube Amplifier Second Harmonic as Millimeter-Wave Beacon Source for Atmospheric Propagation Studies
}

\author{
Rainee N. Simons and Edwin G. Wintucky \\ National Aeronautics and Space Administration \\ Glenn Research Center \\ Cleveland, Ohio 44135
}

\begin{abstract}
This paper presents the design and test results of a CW millimeter-wave satellite beacon source, based on the second harmonic from a traveling-wave tube amplifier and utilizes a novel waveguide multimode directional coupler. A potential application of the beacon source is for investigating the atmospheric effects on Q-band (37 to $42 \mathrm{GHz}$ ) and V/W-band (71 to $76 \mathrm{GHz}$ ) satellite-to-ground signals.
\end{abstract}

\subsection{Introduction}

Because of increasing congestion in available spectrum at the currently used frequency band ( 3 to $30 \mathrm{GHz}$ ) for space-toground data communications, there is now an effort by NASA, other United States Government agencies and the commercial broadband satellite communications industry to develop the millimeter-wave (mm-wave) frequency band for this purpose. The mm-wave band includes frequencies in the Q-band (37 to $42 \mathrm{GHz}$ ) and the V/W-band (71 to $76 \mathrm{GHz}$ ). Prior to the use of these frequency bands for space communications, it is necessary to first rigorously characterize the many atmospheric effects, including rainfall, cloud coverage and gaseous absorption, on RF signal propagation from a spacebased beacon source. For high data rate wide band communications, it will also be necessary to characterize the group delay effects. The design of any operational satellite communication system is intimately tied with the results of the propagation studies.

In the past, NASA Glenn Research Center (GRC) pioneered the development of Ka-band (20 to $30 \mathrm{GHz}$ ) communications by deploying the Advanced Communications Technology Satellite (ACTS) (Refs. 1 and 2). The ACTS served as a test bed in space for several of the new technologies needed for an operational Ka-band system. In addition, the ACTS propagation experiments were instituted to investigate the effect of Earth's atmosphere on the propagation of Ka-band satellite signals (Ref. 1).

In this paper, we present the design and test results of a $\mathrm{CW}$ satellite beacon source, based on the second harmonic from a space traveling-wave tube amplifier (TWTA). The keyenabling component is a rugged, easily constructed, more efficient waveguide based multimode directional coupler (Ref. 3) that extracts the second harmonic signal from the RF output of a high power space TWTA (Ref. 4). The application of the beacon source is for atmospheric propagation studies at Q-band and V/W-band frequencies leading towards the design of robust space-to-ground satellite communications links. A Q-band space TWTA is presently under development at L-3 Communications Electron Technologies Inc., under a contract from NASA GRC.

\subsection{Beacon Architecture}

A simplified schematic of the beacon source is presented in Figure 1.

\subsection{Waveguide Multimode Directional Coupler Design}

The waveguide multimode directional coupler used in the test demonstration is designed and fabricated from two sections of dissimilar waveguides, a primary or larger cross section waveguide for the fundamental frequency and a secondary or smaller cross section waveguide for the second harmonic as illustrated in Figure 2. The two waveguides are joined together and share a common wall. In the primary waveguide, the signal at the fundamental frequency propagates as the dominant $\mathrm{TE}_{10}$ mode. However, the power in the second harmonic signal propagates as higher order modes. If an aperture is cut in the shape of a narrow rectangular slot parallel to the $y$-axis along the primary waveguide narrow wall the coupling to the $\mathrm{TE}_{10}$ mode will be negligibly small. However, the slot aperture will couple strongly to the $\mathrm{TM}_{11}$ type higher order mode. Thus the power in the second harmonic signal is selectively coupled to the secondary waveguide and can be amplified to the power level needed for atmospheric propagation studies.

\subsection{Multimode Directional Coupler Fabrication}

For the initial proof-of-concept (POC) demonstration, the primary and the secondary waveguides were chosen as the WR-62 and WR-28, respectively. Thus, the fundamental frequency is at $\mathrm{Ku}$-band (13.25 to $18 \mathrm{GHz}$ ) and the second harmonic is at Ka-band (26.5 to $36 \mathrm{GHz})$. Figure 3 shows the fabricated POC multimode directional coupler used in the demonstrations. 


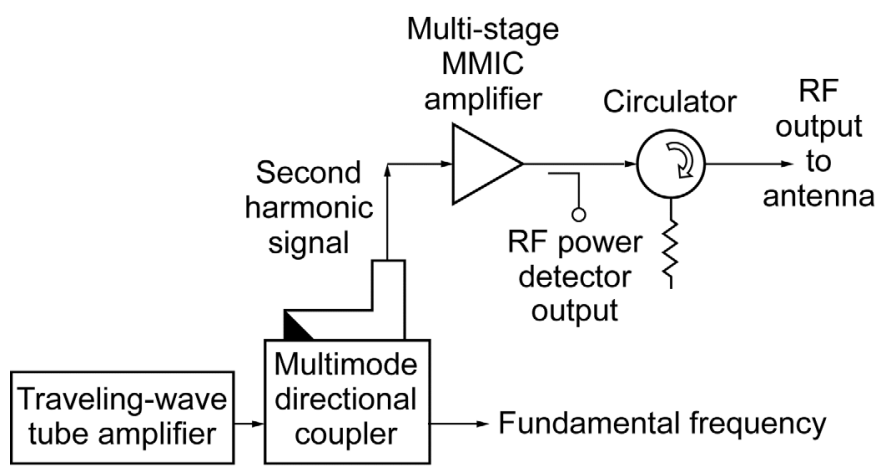

Figure 1.-Simplified schematic of a satellite borne beacon source for RF propagation studies.

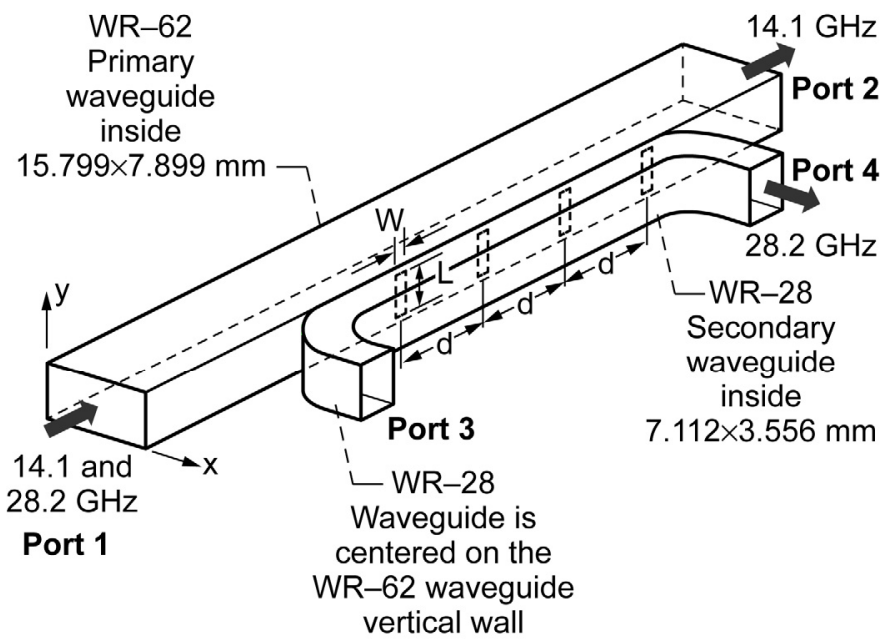

Figure 2.-Schematic of waveguide multimode directional coupler.

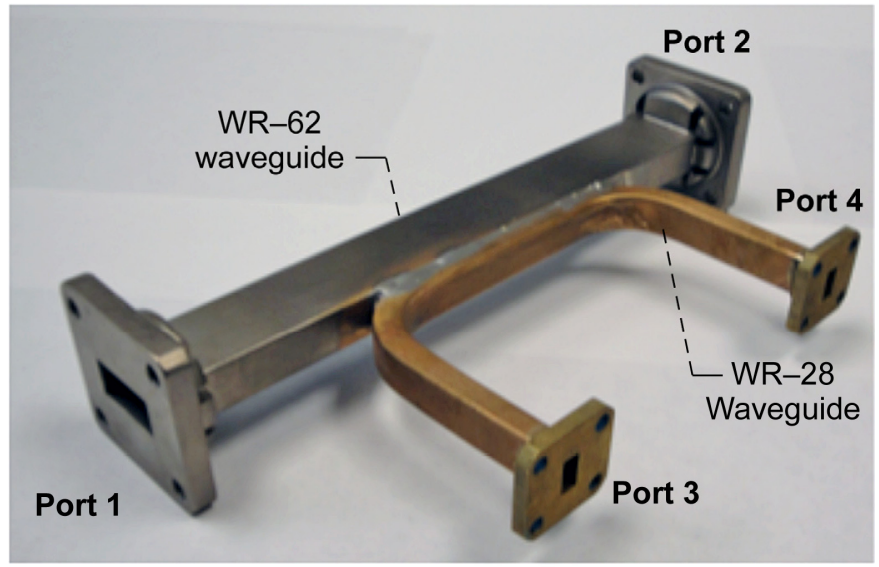

Figure 3.-Fabricated proof-of-concept Ku-band/Ka-band waveguide multimode directional coupler.

\subsection{Multimode Directional Coupler Test Data}

Figure 4 shows the test setup used for the measurement of power at the second harmonic frequencies at the Ka-band secondary waveguide output port of the multimode directional coupler, when the TWTA is operating at saturation and maximum efficiency. The measured power at the second harmonic frequencies over a broad range extending from 27.0 to $30.0 \mathrm{GHz}$ is shown in Figure 5. The test data indicates that there is a significant amount of power in the second harmonic. Typically, beacons used in radio wave propagation studies are narrow band sources (Ref. 1). Hence, a desired beacon signal frequency can be selected from the above range of frequencies and amplified to the desired EIRP level (Ref. 5). It is worth mentioning that the fundamental signal is below the cutoff frequency of the Ka-band secondary waveguide and hence propagates unperturbed in the Ku-band primary waveguide, which is a major advantage over traditional harmonic filters.

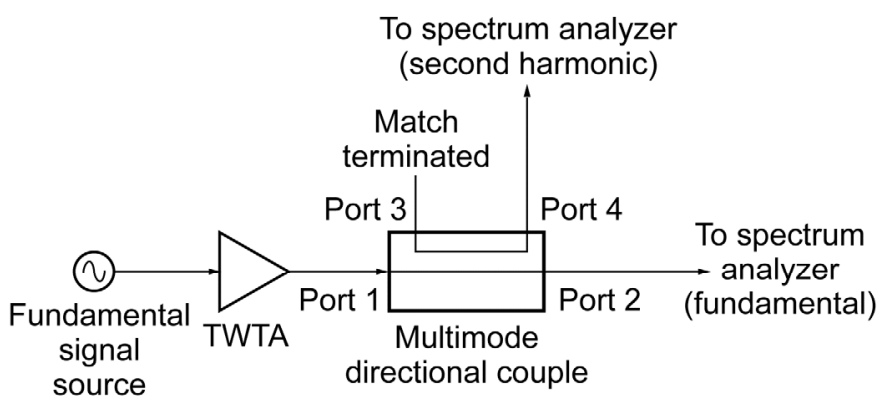

Figure 4.-Test setup for measurement of power at the second harmonic frequencies at port 4 of the multimode directional coupler.

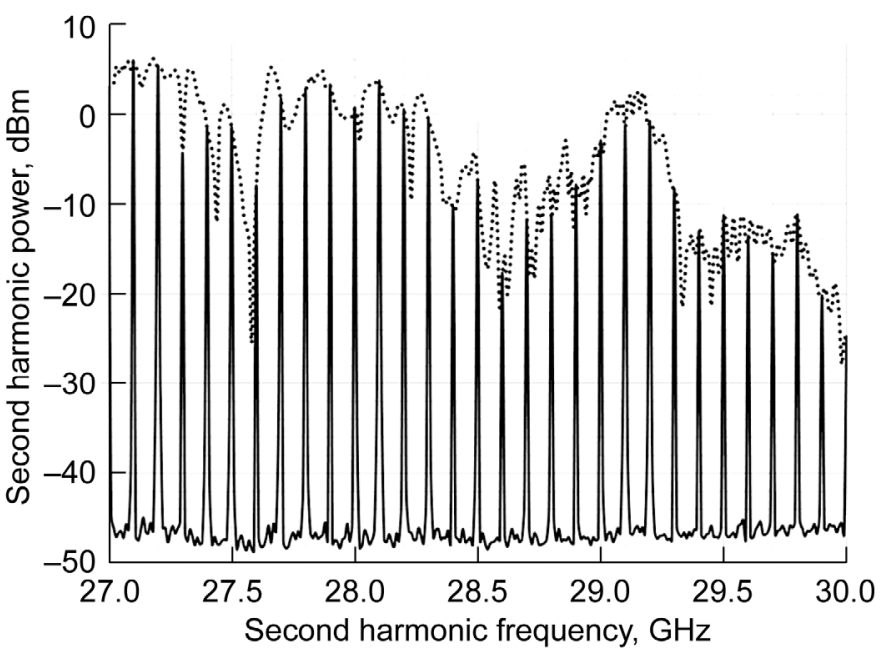

Figure 5.-Measured power at the second harmonic frequencies at port 4 of the multimode directional coupler. 


\subsection{Conclusions}

The design, fabrication and characterization of a novel waveguide multimode directional coupler is presented. An application of the coupler is in a space borne beacon source for atmospheric propagation studies at millimeter-wave frequencies.

\section{References}

1. R. Bauer, "Ka-band Propagation Measurements: An Opportunity with the Advanced Communications Technology Satellite (ACTS)," Proc. IEEE, vol. 85, no. 6, pp. 853-862, June 1997.

2. R.J. Acosta, R. Bauer, R.J. Krawczyk, R.C. Reinhart, M.J. Zernic, F. Gargione, "Advanced Communications Technology Satellite (ACTS): Four-Year System Performance," IEEE Jour. Selected Areas in Communications, vol. 17, no. 2, pp. 193-203, Feb. 1999.
3. Patent Application Filed with the U.S.P.T.O.

4. R.N. Simons, J.D. Wilson, and D.A. Force, "High power and efficiency space traveling-wave tube amplifiers with reduced size and mass for NASA missions," 2008 IEEE MTT-S International Microwave Symposium Digest, pp. 319-322, Atlanta, GA, June 15-20, 2008.

5. R.N. Simons and E.G. Wintucky, "Q-Band (37-41 GHz) Satellite Beacon Architecture for RF Propagation Experiments," 2012 IEEE Antennas and Propagation International Symposium Digest, Chicago, IL, July 8-14, 2012. 


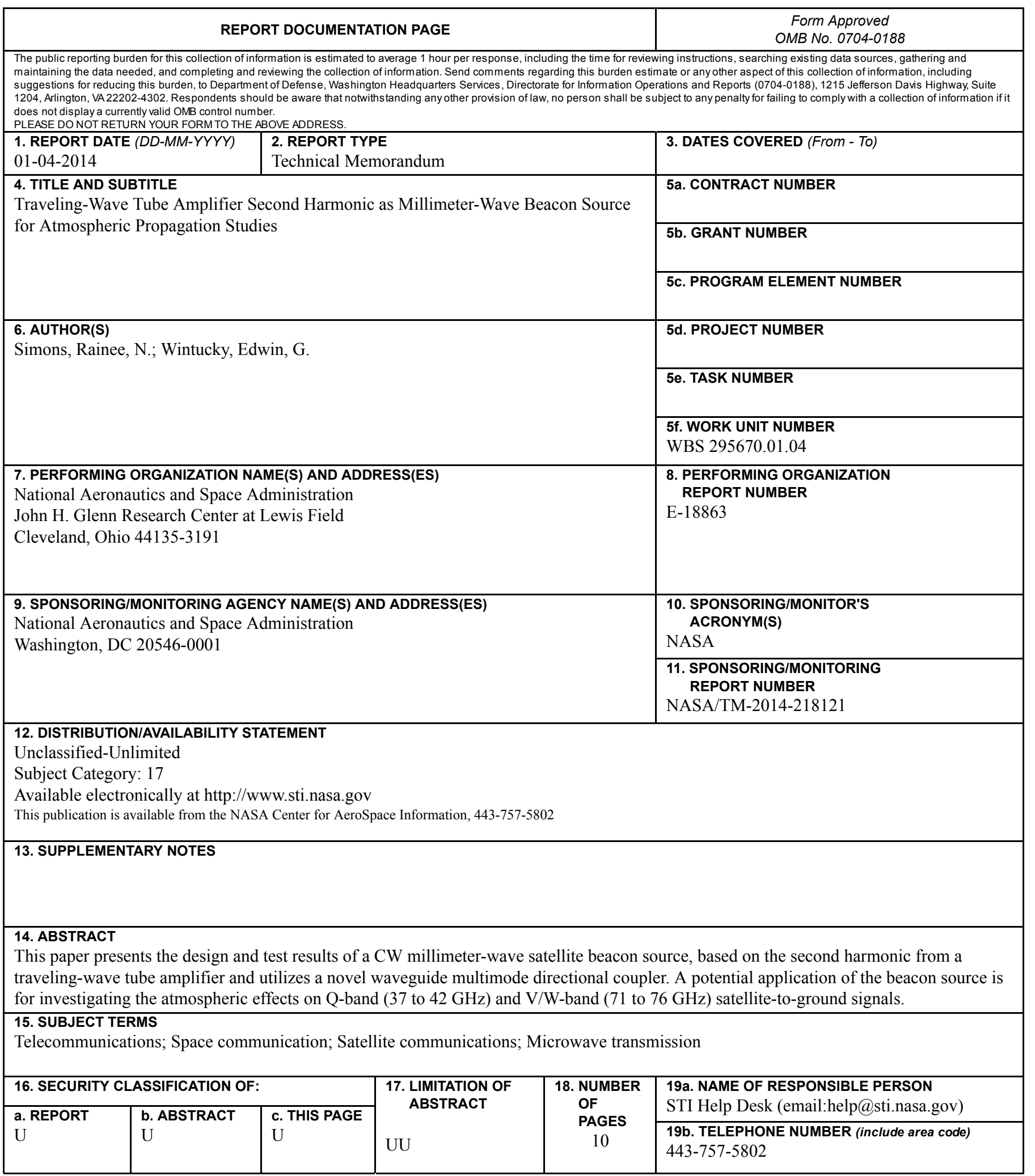



